\title{
Sugar sweetened beverages attributable disease burden and the potential impact of policy interventions: a systematic review of epidemiological and decision models
}

Andrea Alcaraz ${ }^{1 *}$, Andrés Pichon-Riviere ${ }^{1,2,3}$, Alfredo Palacios ${ }^{1}$, Ariel Bardach ${ }^{1,2}$, Dario Javier Balan ${ }^{1}$, Lucas Perelli ${ }^{1}$, Federico Augustovski, ${ }^{1,2}$ and Agustín Ciapponi, ${ }^{1,2}$

\begin{abstract}
Background: Around 184,000 deaths per year could be attributable to sugar-sweetened beverages (SSBs) consumption worldwide. Epidemiological and decision models are important tools to estimate disease burden. The purpose of this study was to identify models to assess the burden of diseases attributable to SSBs consumption or the potential impact of health interventions.

Methods: We carried out a systematic review and literature search up to August 2018. Pairs of reviewers independently selected, extracted, and assessed the quality of the included studies through an exhaustive description of each model's features. Discrepancies were solved by consensus. The inclusion criteria were epidemiological or decision models evaluating SSBs health interventions or policies, and descriptive SSBs studies of decision models. Studies published before 2003, cost of illness studies and economic evaluations based on individual patient data were excluded.

Results: We identified a total of 2766 references. Out of the 40 included studies, $45 \%$ were models specifically developed to address SSBs, $82.5 \%$ were conducted in high-income countries and $57.5 \%$ considered a health system perspective. The most common model's outcomes were obesity/overweight (82.5\%), diabetes (72.5\%), cardiovascular disease (60\%), mortality (52.5\%), direct medical costs $(57.35 \%)$, and healthy years -DALYS/QALYs(40\%) attributable to SSBs. $67.5 \%$ of the studies modelled the effect of SSBs on the outcomes either entirely through BMI or through BMI plus diabetes independently. Models were usually populated with inputs from national surveys -such us obesity prevalence, SSBs consumption-; and vital statistics (67.5\%).

Only 55\% reported results by gender and $40 \%$ included children; 30\% presented results by income level, and 25\% by selected vulnerable groups. Most of the models evaluated at least one policy intervention to reduce SSBS consumption (92.5\%), taxes being the most frequent strategy (75\%).
\end{abstract}

\footnotetext{
*Correspondence: aalcaraz@iecs.org.ar

${ }^{1}$ Instituto de Efectividad Clínica y Sanitaria (IECS) /Institute for Clinical

Effectiveness and Health Policy, Buenos Aires, Argentina

Full list of author information is available at the end of the article
} 
Conclusions: There is a wide range of modelling approaches of different complexity and information requirements to evaluate the burden of disease attributable to SSBs. Most of them take into account the impact on obesity, diabetes and cardiovascular disease, mortality, and economic impact. Incorporating these tools to different countries could result in useful information for decision makers and the general population to promote a deeper implementation of policies to reduce SSBs consumption.

PROSPERO protocol number: CRD42020121025.

Keywords: Sugar sweetened beverages (SSBs), Burden of disease, Economic evaluations, Decision models, Epidemiological models, Health policies

\section{Background}

Non-communicable diseases (NCD) were responsible for more than $50 \%$ of the global health burden in 2013 , accounting for 38.3 million deaths worldwide [1]. About $80 \%$ of these premature NCD deaths occur in low- and middle-income countries (LMICs) [2]. Additionally, these non-communicable diseases have a huge attributable cost on health systems as well as to the society as a whole [3-8]. This enormous disease burden represents a major barrier to the achievement of the Millennium Development Goals [2].

Obesity is an important determinant of the burden of disease currently attributable to NCDs. In 2015, nearly 110 million children and more than 600 million adults were obese [9]. Since 1980, the prevalence of obesity has doubled in more than 70 countries and has continuously increased in most other countries [10]. The proportion of overweight or obese adults increased between 1980 and 2013 from 28.8 to $36.9 \%$ in men, and from 29.8 to $38.0 \%$ in women around the world [11]. Obesity-attributable diseases cause more than 17 million global deaths each year $[9,12]$. The rates of childhood overweight and obesity have increased across all age and socioeconomic status (SES) groups. These trends have been remarkable in highly urbanized areas. Obese children are at increased risk of type 2 diabetes, high blood pressure, asthma, sleep disorders, liver disease, low self-esteem, depression and social isolation, and obese adults are more prone to cardiovascular diseases (CVD) and obesity-related cancers [13, 14].

Obesity is a multi-causal phenomenon, that includes unhealthy dietary patterns and sedentarism, among others. Dietary surveys indicate that foods and beverages high in free sugars can constitute a major source of discretionary calories: added sugars supply food energy but no other nutrients (also called "empty calories").

Sugar sweetened beverages (SSBs) consumption has been linked to an increased risk of type 2 diabetes, obesity [13-15], obesity-related cancers [16], hypertension [17], coronary heart disease [15], and tooth decay [1823]. Dental burden can also represent $5-10 \%$ of healthcare budgets in industrialized countries, and even more so in low-income countries $[24,25]$.
Worldwide, it has been estimated that 184,000 deaths per year could be attributable to SSBs consumption: 133000 from diabetes mellitus, 45,000 from CVD, and 6450 from cancers [26]. .SSB consumption varies considerably by geographic location, gender, age and socioeconomic status. The mean daily SSB consumption among adults was estimated at $137 \mathrm{~mL}$ (95\% CI: 88 to $211 \mathrm{~mL}$ ) in 2010 and is usually higher younger persons, low-income groups and among males [26], with large disparities between countries. These beverages include soft drinks, sodas, fruit drinks, sweetened coffees and teas, energy drinks, sports drinks, and sweetened waters. SSB constitutes the single largest source of added sugars in the American diet, and over 5\% of overall caloric intake $[27,28]$. Although full-calorie beverage consumption is declining, beverage consumption as a whole is increasing, especially with the mid-calorie drinks (e.g., sports drinks, teas, and energy drinks) [29].

Although many countries around the world are considering, or have begun to implement, a series of measures aimed at tackling SSB consumption, there is also a lack of awareness of this topic from decision-makers, stakeholders and the general population. Furthermore, many interventions (such as tax increases) meet with resistance. There is a wide range of interventions wherein decision makers and key leaders of various sectors are involved; the spectrum includes fiscal policies taxings $\mathrm{SSB}$, front of package regulations, educational measures, modification of the school environment, publicity bans, promotion and sponsorship, among other interventions [30-34]. .Having information on the burden of disease such as the impact on health and the economics of SSB consumption as well as cost-effectiveness and the expected impact of implementing public health policies could facilitate moving forward [22].

Assessments based on epidemiological and decision models are widely accepted as decision-making tools and can provide valuable information for optimizing the allocation of health resources [35].

This study is part of a larger multi-country study funded by the International Development Research Centre (IDRC) and oriented to empowering healthcare 
decision makers to achieve regional needs in SSB policies in Latin America and the Caribbean through the evaluation of disease and economic burden, as well as the cost-effectiveness of available interventions.

The purpose of the study was to identify epidemiological or decision models to assess the burden of disease attributable to SSB consumption or the costeffectiveness of interventions aimed at reducing SSB consumption, to describe the different methodological approaches through a systematic review. In other words, which are the best available published models applicable to assess SSB related problems?

\section{Methods}

A systematic review of the published literature was carried out according to the reporting parameters proposed in the guidelines: Preferred reporting items for systematic reviews and meta-analyses (PRISMA) [36].

We undertook a systematic search up to August 2018 in the following biomedical bibliographic databases: MEDLINE (Ovid), Cochrane (Wiley), EMBase (Elsevier), CINAHL (EBSCO), LILACS (iAH). Details about the performed electronic searches are provided in the Additional file 1. Search strategy. For further information we also hand-searched reference-lists of published systematic reviews (SR) of models and performed a prospective citation tracking.

\section{Selection process, eligibility, and risk of bias (quality) assessment}

Pairs of reviewers independently selected articles, initially by title and abstract and subsequently by evaluating the full texts of studies meeting the inclusion criteria, using the software Covidence [37, 38]. For article eligibility, the following criteria were established: 1) epidemiological or decision models exploring SSBs-related disease burden which report attributable deaths and at least one of the following outcomes: Disability-Adjusted Life Years (DALYs), Quality-Adjusted Life Years (QALYs), and Years of Life Lost (YLLs), 2) model-based economic evaluations of health interventions or policies, implemented or implementable at the city, state, or national level, and 3) descriptive studies of decision models that explore disease burden or cost-effectiveness. The exclusion criteria were: 1) publishing date before the year 2003 -since the relationship between SSBs and health risk was not previously clear-, 2) cost-only studies (health effects not included), 3) models not specifically about SSBs or which do not distinctively show SSBs effects, 4) economic evaluations based only on randomized controlled trials (piggyback studies). Based on the paper by Brennan et al. paper [39] we defined a model as a formal quantified comparison, which summarize sources of evidence on costs and benefits, in order to identify the best option for decision makers to adopt. These authors additionally proposed a model taxonomy according to different dimensions. We simplified this taxonomy to account for different model characteristics: whether they incorporated interactions between the individuals; whether they were epidemiological (a simple usually excel based model), aggregated (nonindividual) or at individual level; how they handled the time variable (as a continuous variable, as discrete steps/cycles or were untimed); or were based on cohorts (state-transition/ Markov models).

Pairs of reviewers independently extracted data using a previously piloted data extraction form and assessed the risk of bias (quality) of the included studies. In case of disagreements, it was resolved by consensus. If reaching a consensus proved to be difficult, a third author made the final decision. Considering the nature of our research question, a specific risk of bias (quality) assessment tool was not deemed to be applicable. Nevertheless, we used the items in the data extraction template to assess the exhaustiveness of the model features and description.

\section{Data synthesis}

We performed a descriptive synthesis of the main characteristics of the identified models.

For each model we considered its type, frequency of use in public health, specificity for SSBs- attributable effects, time horizon, perspective, age, sex, SES and countries of application to allow subgroup analyses. We assessed the following features: presence of interaction between individuals, degree of information aggregation (individual, aggregate, econometric or epidemiological), temporal dimension incorporation, and number of cohorts required (single cohort vs multicohort). Regarding model inputs, we specified data requirements such as incidence, data by condition, vital data, longitudinal data, representative surveys, or other data.

As for outcomes, we analyzed if they reported: variations in the degree of consumption, obesity/overweight, diabetes, mortality, cardiovascular disease, cancer, tooth cavities, bullying, other health outcomes; DALYs, QALYs or YLL; direct or indirect costs; tax revenue, sales of sugary drinks and health equity aspects. For cost-effectiveness models we also considered which type of intervention was being evaluated: taxation, school environment modifications, advertising, labeling, or others. We estimated the workload needed to complete populating models according to their type, as well as their applicability to the Latin-American and Caribbean context. In all cases they scored as low, medium or high effort /applicability and the final decision was reached by group consensus. 
Finally, we identified each model's underlying disease causal pathway and graphically assigned it to a group according to its pathway and / or the manner in which results were reported.

\section{Results}

We identified a total of 2766 references from the bibliographic databases (2709 after removal of duplicates). We selected 87 of those for eligibility by full text-screening and we finally included 40 studies $[18,23,25-27,32$, 40-73] published between 2012 and 2018 (See Fig. 1. Study flow diagram).

The descriptive statistics of the characteristics of the included SSBs models are described in Tables 1 and 2. A detailed description of each model's features, taxonomy, inputs, results, subgroups analyzed, interventions evaluated, and applicability can be found in Additional file 2 . Tables 1 to 5 . These characteristics were considered as an indirect proxy of the study quality.

Out of the 40 included studies only $45 \%$ were exclusive for SSBs, while in the rest of the models SSBs was one of the risk factors evaluated among others (e.g., obesity or cardiovascular risk factors). $72.5 \%$ analyzed a maximum time horizon of 10 or more years; only $25 \%$ considered child population separately. Only $12.5 \%$ included a Latin-American country while $82.5 \%$ were conducted in high income countries, mainly in USA, Australia and the UK. Most models were based on healthcare system perspective (57.5\%).

Regarding the model taxonomy, none incorporated interactions between the individuals; most were classified as epidemiological (42.5\%), aggregated -non individuallevel (35.5\%), timed (50\%), and based on cohort (62.5\%). A detailed description of each model can be found in Additional file 2. Table 6.

The majority of the models involve moderate applicability efforts or requirements (85\%) and show moderate applicability to Latin-America and the Caribbean region (87.5\%).

Most models required inputs from national surveys -such as obesity prevalence, SSBs consumption-; vital statistics (67.5\%) mainly related to specific disease mortality; and each country's disease incidence (52.5\%). See Table 1.

The most common results provided by the burden of disease models were obesity/overweight (82.5\%), diabetes

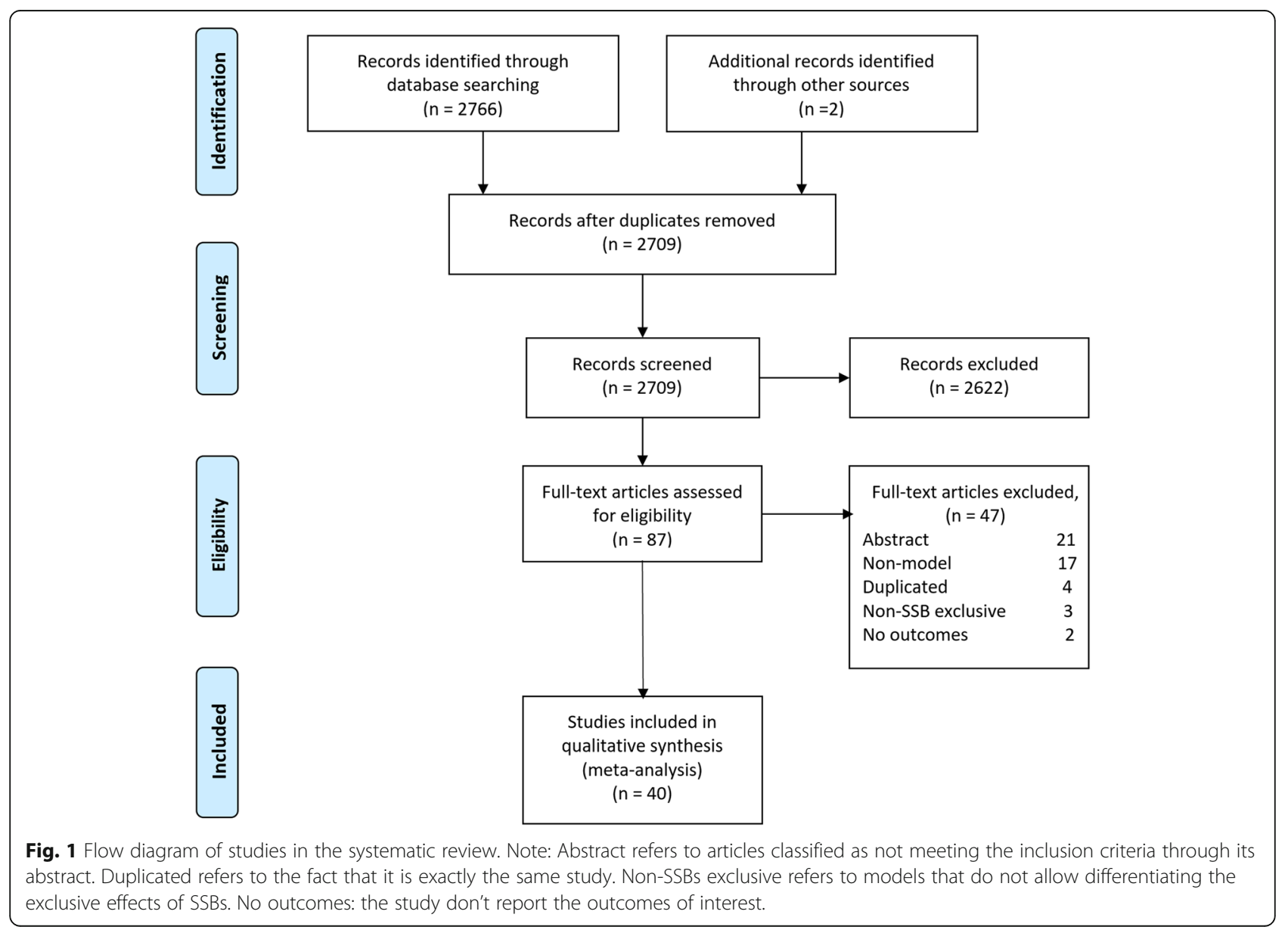


Table 1 Descriptive statistics of the included SSBs models: features, taxonomy, and applicability

\begin{tabular}{|c|c|c|c|}
\hline Model & Descriptive variables & Frequency ( $N=40$ studies) & $\%$ \\
\hline \multirow[t]{14}{*}{ Features } & Specific to SSBs & $N=18$ & $45.0 \%$ \\
\hline & \multirow[t]{4}{*}{ Time horizon (maximum) } & 1 year $=8$ & $22.5 \%$ \\
\hline & & $2-10$ years $=14$ & $35.0 \%$ \\
\hline & & $11-25$ years $=9$ & $22.5 \%$ \\
\hline & & Lifetime $=8$ & $20.0 \%$ \\
\hline & \multirow[t]{3}{*}{ Population } & Adults only $=21$ & $52.5 \%$ \\
\hline & & Childs only $=2$ & $5.0 \%$ \\
\hline & & Total population $=17$ & $42.5 \%$ \\
\hline & \multirow[t]{3}{*}{ Country by income } & High income $=30$ & $75,00 \%$ \\
\hline & & Low and middle income $=9$ & $22,50 \%$ \\
\hline & & Worldwide $=1$ & $2,50 \%$ \\
\hline & \multirow[t]{3}{*}{ Perspective } & Government $=6$ & $15.0 \%$ \\
\hline & & Health system $=23$ & $57.5 \%$ \\
\hline & & Societal = 11 & $27.5 \%$ \\
\hline \multirow[t]{12}{*}{ Taxonomy } & Interaction allowed & $N=0$ & $0 \%$ \\
\hline & \multirow[t]{4}{*}{ Aggregate/ Individual/ econometric/ epidemiological } & Aggregate $=14$ & $35.0 \%$ \\
\hline & & Individual = 1 & $2.5 \%$ \\
\hline & & Econometric $=8$ & $20.0 \%$ \\
\hline & & Epidemiological $=17$ & $42.5 \%$ \\
\hline & \multirow[t]{4}{*}{ Time incorporation } & Timed $=20$ & $50.0 \%$ \\
\hline & & Untimed $=13$ & $32.5 \%$ \\
\hline & & Continuous $=6$ & $15.0 \%$ \\
\hline & & Not applicable $=1$ & $2.5 \%$ \\
\hline & \multirow[t]{3}{*}{ Cohort } & Cohort $=25$ & $62.5 \%$ \\
\hline & & Multi-cohort $=8$ & $20.0 \%$ \\
\hline & & Not reported/applicable $=7$ & $17.5 \%$ \\
\hline \multirow[t]{5}{*}{ Applicability } & \multirow[t]{3}{*}{ Effort / requirements } & Low $=4$ & $10.0 \%$ \\
\hline & & Moderate $=34$ & $85.0 \%$ \\
\hline & & High $=2$ & $5.0 \%$ \\
\hline & \multirow[t]{2}{*}{ Applicability / reproducibility } & Moderate $=35$ & $87.5 \%$ \\
\hline & & High $=5$ & $12.5 \%$ \\
\hline
\end{tabular}

(72.5\%), cardiovascular disease (60\%), mortality $(52.5 \%)$, direct medical costs (57.35\%), and DALYs/QALYs (40\%) attributable to SSBs. Only two models incorporate diseases not related to obesity such as cavities. Equity analysis was considered in one third of the studies. Models that evaluated the impact of interventions also included the variation in SSBs consumption (85\%) but only $17.5 \%$ reported tax collection or SSBs sales.

Regarding the analysis of different population subgroups, $55 \%$ reported results by gender and $40 \%$ included children; only $30 \%$ of the models presented results by income level, and only $25 \%$ by vulnerable groups.

Most of the models evaluated at least one intervention (92.5\%), taxes being the most evaluated intervention
(75\%) followed by school environments (12.5\%) and advertising (10\%). See Table 2.

After analyzing each model causal (structural) pathway, we grouped them in six main pathway patterns, which are graphically presented in Fig. 2 Models' pathways groups; complemented by the data in Table 3 . The most frequent pathway (35\%) included the effects of SSBs intake on BMI with the mortality and quality of life of the obesity plus the effects of diabetes and other related diseases/conditions including mortality, DALYS/ QALYs and the cost associated with their treatment. A similar pathway that was almost as frequent (32.5\%) did not consider diabetes independently, but it was included with all the other conditions (mainly cardiovascular 
Table 2 Descriptive statistics of the included SSBs models: inputs, results, subgroups, and interventions

\begin{tabular}{|c|c|c|c|}
\hline Model & Descriptive variables & Frequency ( $N=40$ studies) & $\%$ \\
\hline \multirow[t]{5}{*}{ Inputs } & Incidence & $N=21$ & $52.5 \%$ \\
\hline & Vital statistics & $N=27$ & $67.5 \%$ \\
\hline & Longitudinal data & $N=9$ & $22.5 \%$ \\
\hline & Population survey & $N=37$ & $87.5 \%$ \\
\hline & Demand elasticity & $N=11$ & $27.5 \%$ \\
\hline \multirow[t]{18}{*}{ Results } & Obesity/Overweight & $N=36$ & $90.0 \%$ \\
\hline & Diabetes & $N=29$ & $72.5 \%$ \\
\hline & Cardiovascular disease & $N=31$ & $77.5 \%$ \\
\hline & Cancer & $N=13$ & $32.5 \%$ \\
\hline & Cavities & $N=2$ & $5.0 \%$ \\
\hline & Osteoarthritis & $N=2$ & $5.0 \%$ \\
\hline & Incidence & $N=3$ & $7.5 \%$ \\
\hline & Prevalence & $N=6$ & $15.0 \%$ \\
\hline & Mortality & $N=21$ & $52.5 \%$ \\
\hline & Life years & $N=11$ & $27.5 \%$ \\
\hline & DALYS/QALYS & $N=16$ & $40.0 \%$ \\
\hline & Direct costs & $N=23$ & $57.5 \%$ \\
\hline & Indirect costs & $N=6$ & $15.0 \%$ \\
\hline & Cost-effectiveness & $N=7$ & $17.5 \%$ \\
\hline & Variation in consumption & $N=34$ & $85.0 \%$ \\
\hline & SSBs sales & $N=7$ & $17.5 \%$ \\
\hline & Tax collection & $N=7$ & $17.5 \%$ \\
\hline & Equity & $N=13$ & $32.5 \%$ \\
\hline \multirow[t]{4}{*}{ Subgroups } & Children/teenage & $N=16$ & $40.0 \%$ \\
\hline & Gender & $N=22$ & $55.0 \%$ \\
\hline & Income level & $N=12$ & $30.0 \%$ \\
\hline & Vulnerable groups & $N=10$ & $25.0 \%$ \\
\hline \multirow[t]{5}{*}{ Interventions evaluated } & Taxes & $N=30$ & $75.0 \%$ \\
\hline & School environment & $N=5$ & $12.5 \%$ \\
\hline & Advertising & $N=4$ & $10.0 \%$ \\
\hline & Labelling & $N=2$ & $5.0 \%$ \\
\hline & Subsidies & $N=2$ & $5.0 \%$ \\
\hline
\end{tabular}

SSBs sugar sweetened beverages. Demand elasticity is an economic measure of the sensitivity of demand of SSBs relative to a change in another variable, usually the price. Vulnerable groups: ethnicity, rural status, literacy, education level or participants of a nutritional assistance program

disease and cancer) (see Fig. 2, groups 2 and 3). Models that used the simplest pathway, which only include SSBs intake to BMI represent $17.55 \%$ of the cases. Other pathways were less frequent or not used at all. Each model pathway is graphically represented in figures in Additional file 3 . Pathways by study.

\section{Discussion}

Our systematic review offers a unique and up to date snapshot of current SSBs models, and provides a detailed description of the 40 included studies involving model features, inputs, results, pathways, interventions and applicability issues. This can significantly facilitate the use, adaptation, or development of future models that will improve the current tools aiming to implement a successful SSBs policy.

Remarkably, less than half of the models were specifically designed for SSBs, though all of them provided useful information in order to facilitate the use and adapt or develop a model in future endeavors. The information identified can be used in different contexts; we incorporated information from five continents, including some global approaches [25] and from all perspectives, such as healthcare systems, governments and society as a whole. 


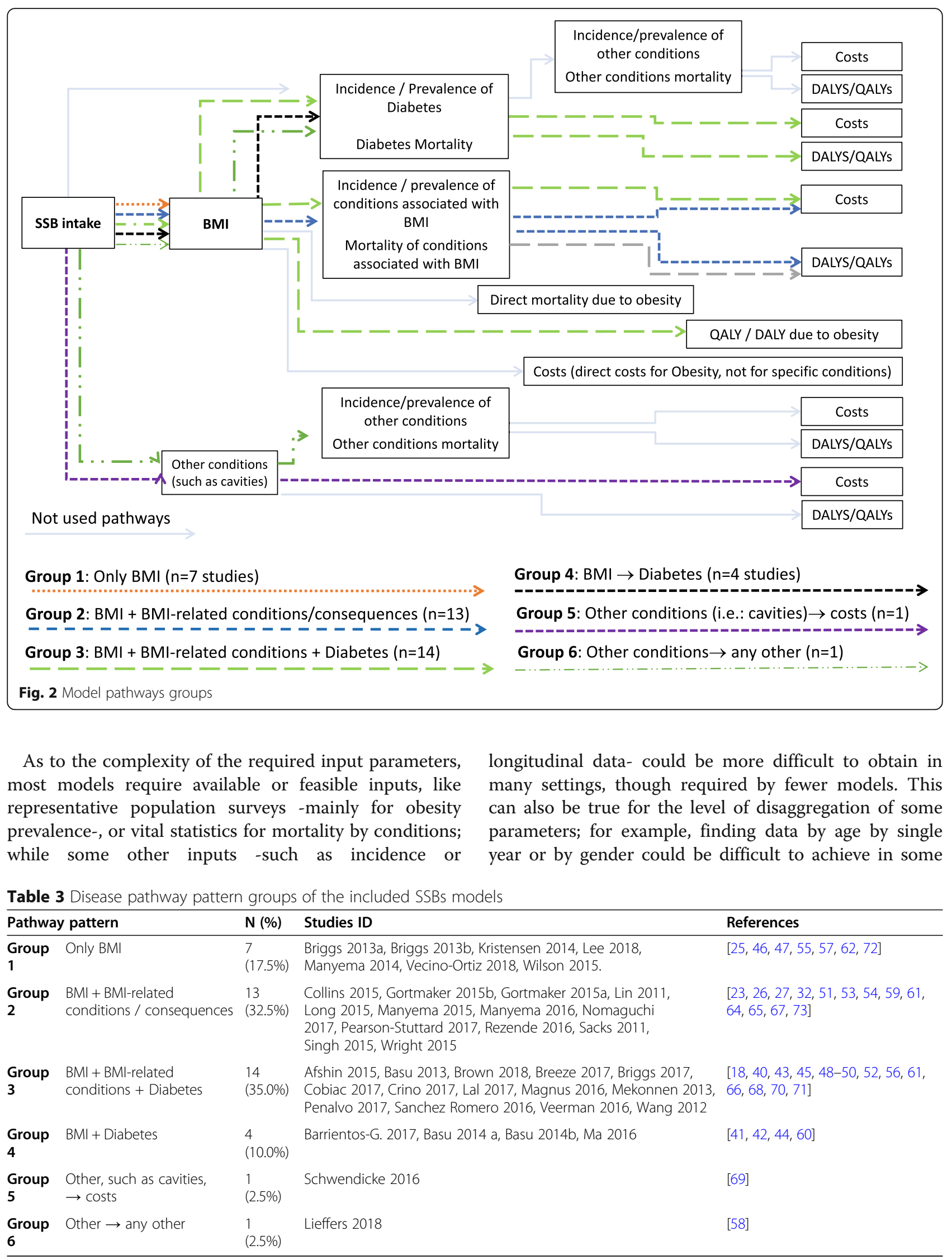


countries or regions. Information regarding SSBs consumption could be difficult to find in Latin-American and the Caribbean countries and specific information on children is usually unavailable. Additionally, the models that evaluating the impact of a required intervention required demand elasticity for SSBs, ideally by age and gender groups, which data is not easily available in many countries.

Models offer relevant results to assess the burden of disease and / or the cost-effectiveness of interventions including the expected variation on SBBs consumption of different policies, obesity/overweight, diabetes, cardiovascular disease, and mortality. Many of the models do not report results in a sufficiently disaggregated manner, thus limiting their applicability and usefulness to end users such as decision makers. The evidence identifies presents some limitations. SSBs consumption is really dissimilar among subgroups, for example adolescents usually consumes more than adults and there are big differences between genders by ages groups or income quintiles [74]. Moreover, the prevalence of obesity and disease has different effects according to gender, age, and income $[10,75,76]$; so it is really usefully to have the opportunity to analyze the effects of SSBs in a disaggregated manner.

Direct and indirect costs and quality of life -DALYs and QALYs- are measures which usually serve as a guide for resource allocation and are valuable for decision makers; but only 57.5 and $40 \%$ of the models incorporated them, respectively. Children were usually omitted in most of the studies, even though they are a widely affected population and a high-priority target for the prevention policies advocated by international organizations such as UNICEF and by numerous health systems.

It is encouraging that most of the interventions studied are those most grounded on evidence such as taxes, school food policies and advertising [77, 78].

Our results show that a variety of specific modelling approaches to SSBs consumption has been used to understand its associated burden. Most of the published studies model the effects of SSBs consumption through increased BMI and the consequences for health -and sometimes for quality of life and the cost- implied. While sometimes the models separate the effects of diabetes, the effect through BMI is invariably considered without including the direct effect of SSBs on diabetes as well [79]. A direct effect of SSBs on cardiovascular disease has been recently recognized (independently of BMI), which no model had previously included [80]. The Australian Assessing Cost-Effectiveness (ACE) model [81] was the most frequently used model, including adaptations to the USA [50, 52-54, 56, 59, 64, 67, 70, 73]. This model is both time- and data- consuming and requires researchers and users to have a high level of understanding of modelling issues, so it is probably difficult to apply in many countries. Our review finds many other model and model causal pathways that could be used. The selection of the appropriate model for each country could depend on the availability of local data, the time horizon selected, the health policy to be evaluated, among others.

A systematic review evaluating the impact of taxes on SSBs according to socio-economic status uncovered that models are focused on SSBs consumption rather than on the burden of disease; few models evaluate the impact on BMI but most of them only evaluated the impact on SSBs consumption [82]. We similarly found out that few studies specifically disaggregated results according to income groups.

Worldwide -and more so in low- and middle-income countries- the general population and decision-makers are not yet fully aware of the dimension of the problem that an excessive SBBs consumption can cause; therefore, studies estimating the attributable disease burden are really important. Also, the interventions that need to be implemented -taxes, labeling, publicity limitation, school environment modifications- are both politically and socially sensitive, and the beverage industry frequently obstructs their implementation [83]. While SSBs taxes have been instituted in over 40 countries and cities [84], the epidemiological shift towards NCDs diseases in low- and middle-income countries (LMICs) warrants the implementation of an even stricter SSBs control policy encompassing all the effective interventions available [77, 78].

The value of non-communicable disease modelling to inform health policy is well established [85-87]. These models guide decision-makers in the implementation of policies to improve risk factors for chronic diseases. The tobacco experience has shown that the burden of disease and economic evaluations have promoted an effective WHO framework implementation all around the world [88]. Four our SSBs-related focus, we found 40 published models that attempt to assess this information on burden of disease that could guide and promote the implementation of evidencebased policies aiming to decrease SSBs consumption and its associated burden. Implementing effective SSBs policies is particularly important for LMICs with double nutritional burden of malnutrition and obesity.

Based on this information each country could select a simple or a more advanced model to apply within its boundaries and also identify what the main inputs and results that could be useful for making decisions in the local context are.

\section{Conclusions}

There is a wide range of modelling approaches with different complexities and information requirements to 
evaluate the burden of disease attributable to SSBs. The majority of these approaches consider the impact on obesity, diabetes and cardiovascular disease, mortality, and economic impact. The incorporation of these tools in different countries could generate useful information for decision makers and the general population and promote a deeper implementation of policies to diminish SSBs consumption.

\section{Supplementary Information}

The online version contains supplementary material available at https://doi. org/10.1186/s12889-021-11046-7.

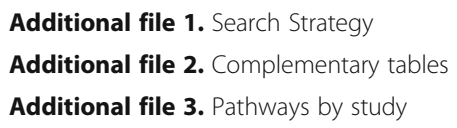

\section{Acknowledgments}

Daniel Comandé, Mónica Soria, Natalie Soto, María Belén Rodriguez, Sebastian García Marti.

\section{Authors' contributions}

AA coordinated the overall activities, designed the strategies, extracted data, plan the analysis, discussed the results and write the final draft. AC designed the strategies, extracted, plan and analyze data, discussed the results and write the final draft. APR, AP, AB y FA designed the strategies, extracted data, plan the analysis and discussed the results. DB and LP extracted data and discussed the results. All authors contributed to the interpretation of the results and contributed to edit the final draft. The author(s) read and approved the final manuscript.

\section{Funding}

International Development Research Centre (IDRC) Project Number-Activity Number-Component Number: 108646-001. The sponsor supported all the activities and material needed to achieve the project objective, but it was not involved in any stage of the study.

\section{Availability of data and materials}

The datasets used and/or analysed during the current study are available from the corresponding author on reasonable request.

\section{Declarations}

Ethics approval and consent to participate

Not applicable.

\section{Consent for publication}

Not applicable.

\section{Competing interests}

The authors declare that they have no competing interests.

\section{Author details}

${ }^{1}$ Instituto de Efectividad Clínica y Sanitaria (IECS) /Institute for Clinical Effectiveness and Health Policy, Buenos Aires, Argentina. ${ }^{2}$ Consejo Nacional de Investigaciones Científicas y Técnicas (CONICET), Buenos Aires, Argentina. ${ }^{3}$ Escuela de Salud Pública, Facultad de Medicina, Universidad de Buenos Aires (UBA), Buenos Aires, Argentina.

Received: 9 January 2021 Accepted: 26 April 2021

Published online: 27 July 2021

\section{References}

1. Murray CJ, Vos T, Lozano R, Naghavi M, Flaxman AD, Michaud C, et al. Disability-adjusted life years (DALYs) for 291 diseases and injuries in 21 regions, 1990-2010: a systematic analysis for the global burden of disease study 2010. Lancet. 2012;380(9859):2197-223. https://doi.org/10.1016/S01406736(12)61689-4.

2. Beaglehole R, Bonita R, Horton R, Adams C, Alleyne G, Asaria P, et al. Priority actions for the non-communicable disease crisis. Lancet. 2011;377(9775): 1438-47. https://doi.org/10.1016/S0140-6736(11)60393-0.

3. Sultan-Taieb H, Chastang JF, Mansouri M, Niedhammer I. The annual costs of cardiovascular diseases and mental disorders attributable to job strain in France. BMC Public Health. 2013;13(1):748. https://doi.org/10.1186/1471-24 58-13-748.

4. Seuring T, Archangelidi O, Suhrcke M. The economic costs of type 2 diabetes: a global systematic review. PharmacoEconomics. 2015;33(8):81131. https://doi.org/10.1007/s40273-015-0268-9.

5. Schmid T, Xu W, Gandra SR, Michailov G. Costs of treating cardiovascular events in Germany: a systematic literature review. Value Health. 2014;17(7): A485. https://doi.org/10.1016/j.jval.2014.08.1418.

6. Joo H, Zhang P, Wang G. Cost of informal care for patients with cardiovascular disease or diabetes: current evidence and research challenges. Qual Life Res. 2017;26(6):1379-86. https://doi.org/10.1007/s1113 6-016-1478-0.

7. Gaziano TA. Economic burden and the cost-effectiveness of treatment of cardiovascular diseases in Africa. Heart. 2008;94(2):140-4. https://doi.org/1 $0.1136 /$ hrt.2007.128785.

8. Evans N. Managing the cost of cardiovascular prevention in primary care. Heart. 2004;90(Suppl 4):iv26-8 discussion iv39-40.

9. Guh DP, Zhang W, Bansback N, Amarsi Z, Birmingham CL, Anis AH. The incidence of co-morbidities related to obesity and overweight: a systematic review and meta-analysis. BMC Public Health. 2009;9(1):88. https://doi.org/1 0.1186/1471-2458-9-88.

10. Collaborators GBDO, Afshin A, Forouzanfar $M H$, Reitsma MB, Sur P, Estep K, et al. Health effects of overweight and obesity in 195 countries over 25 years. N Engl J Med. 2017;377(1):13-27. https://doi.org/10.1056/ NEJMoa1614362.

11. Ng M, Fleming T, Robinson M, Thomson B, Graetz N, Margono C, et al. Global, regional, and national prevalence of overweight and obesity in children and adults during 1980-2013: a systematic analysis for the global burden of disease study 2013. Lancet. 2014;384(9945):766-81. https://doi. org/10.1016/S0140-6736(14)60460-8.

12. Lozano R, Naghavi M, Foreman K, Lim S, Shibuya K, Aboyans V, et al. Global and regional mortality from 235 causes of death for 20 age groups in 1990 and 2010: a systematic analysis for the global burden of disease study 2010. Lancet. 2012;380(9859):2095-128. https://doi.org/10.1016/S0140-6736(12)61 728-0.

13. Malik VS, Pan A, Willett WC, Hu FB. Sugar-sweetened beverages and weight gain in children and adults: a systematic review and meta-analysis. Am J Clin Nutr. 2013;98(4):1084-102. https://doi.org/10.3945/ajcn.113.058362.

14. Malik VS, Willett WC, Hu FB. Sugar-sweetened beverages and BMI in children and adolescents: reanalyses of a meta-analysis. Am J Clin Nutr. 2009;89(1):4389; author reply 439-440. https://doi.org/10.3945/ajen.2008.26980.

15. Vos MB, Kaar JL, Welsh JA, Van Horn LV, Feig DI, Anderson CAM, et al. Added sugars and cardiovascular disease risk in children: a scientific statement from the American Heart Association. Circulation. 2017;135(19): e1017-34. https://doi.org/10.1161/CIR.0000000000000439.

16. Lauby-Secretan B, Scoccianti C, Loomis D, Grosse Y, Bianchini F, Straif K. International Agency for Research on Cancer handbook working G: body fatness and Cancer--viewpoint of the IARC working group. N Engl J Med. 2016;375(8):794-8. https://doi.org/10.1056/NEJMsr1606602.

17. Jayalath VH, de Souza RJ, Ha V, Mirrahimi A, Blanco-Mejia S, Di Buono M, et al. Sugar-sweetened beverage consumption and incident hypertension: a systematic review and meta-analysis of prospective cohorts. Am J Clin Nutr. 2015;102(4):914-21. https://doi.org/10.3945/ajcn.115.107243.

18. Mekonnen TA, Odden MC, Coxson PG, Guzman D, Lightwood J, Wang YC, et al. Health benefits of reducing sugar-sweetened beverage intake in high risk populations of California: results from the cardiovascular disease (CVD) policy model. PLoS One. 2013;8(12):e81723. https://doi.org/10.1371/journal. pone.0081723.

19. Wang H, Steffen LM, Zhou X, Harnack L, Luepker RV. Consistency between increasing trends in added-sugar intake and body mass index among adults: the Minnesota heart survey, 1980-1982 to 2007-2009. Am J Public Health. 2013;103(3):501-7. https://doi.org/10.2105/AJPH.2011.300562.

20. de Koning L, Malik VS, Kellogg MD, Rimm EB, Willett WC, Hu FB. Sweetened beverage consumption, incident coronary heart disease, and biomarkers of 
risk in men. Circulation. 2012;125(14):1735-41, S1731. https://doi.org/10.11 61/CIRCULATIONAHA.111.067017.

21. Te Morenga L, Mallard S, Mann J. Dietary sugars and body weight: systematic review and meta-analyses of randomised controlled trials and cohort studies. Bmj. 2012;346(jan15 3):e7492. https://doi.org/10.1136/bmj.e7492.

22. Moynihan PJ, Kelly SA. Effect on caries of restricting sugars intake: systematic review to inform WHO guidelines. J Dent Res. 2014;93(1):8-18. https://doi.org/10.1177/0022034513508954.

23. Rezende LF, Azeredo CM, Canella DS, Luiz Odo C, Levy RB, Eluf-Neto J. Coronary heart disease mortality, cardiovascular disease mortality and allcause mortality attributable to dietary intake over 20years in Brazil. Int J Cardiol. 2016;217:64-8. https://doi.org/10.1016/j.jicard.2016.04.176.

24. Meier T, Deumelandt P, Christen O, Stangl Gl, Riedel K, Langer M. Global burden of sugar-related dental diseases in 168 countries and corresponding health care costs. J Dent Res. 2017;96(8):845-54.

25. Vecino-Ortiz Al, Arroyo-Ariza D. A tax on sugar sweetened beverages in Colombia: estimating the impact on overweight and obesity prevalence across socio economic levels. Soc Sci Med. 2018;209:111-6. https://doi.org/1 0.1016/.socscimed.2018.05.043

26. Singh GM, Micha R, Khatibzadeh S, Lim S, Ezzati M, Mozaffarian D. Estimated global, regional, and National Disease Burdens Related to sugar-sweetened beverage consumption in 2010. Circulation. 2015;132(8):639-66. https://doi. org/10.1161/CIRCULATIONAHA.114.010636.

27. Lin BH, Smith TA, Lee JY, Hall KD. Measuring weight outcomes for obesity intervention strategies. The case of a sugar-sweetened beverage tax. Econ Hum Biol. 2011;9(4):329-41. https://doi.org/10.1016/j.ehb.2011.08.007.

28. Huth PJ, Fulgoni VL, Keast DR, Park K, Auestad N. Major food sources of calories, added sugars, and saturated fat and their contribution to essential nutrient intakes in the U.S. diet: data from the National Health and Nutrition Examination Survey (2003-2006). Nutr J. 2013;12:116.

29. Pomeranz JL, Munsell CR, Harris JL. Energy drinks: an emerging public health hazard for youth. J Public Health Policy. 2013;34(2):254-71. https:// doi.org/10.1057/jphp.2013.6.

30. Roberto CA, Swinburn B, Hawkes C, Huang TT, Costa SA, Ashe M, et al. Patchy progress on obesity prevention: emerging examples, entrenched barriers, and new thinking. Lancet. 2015;385(9985):2400-9. https://doi.org/1 0.1016/S0140-6736(14)61744-X.

31. von Philipsborn PSJ, Burns J, Busert LK, Pfadenhauer LM, Polus S, Holzapfel $C$, et al. Environmental interventions to reduce the consumption of sugarsweetened beverages and their effects on health. Cochrane Database Syst Rev. 2016;7:CD012292.

32. Manyema M, Veerman JL, Chola L, Tugendhaft A, Labadarios D, Hofman K. Decreasing the burden of type 2 diabetes in South Africa: the impact of taxing sugar-sweetened beverages. PLoS One. 2015;10(11):e0143050. https:// doi.org/10.1371/journal.pone.0143050.

33. Cobiac $L$, Tam K. Taxes and Subsidies for Improving Diet and Population Health in Australia: A Cost-Effectiveness Modelling Study. 2017;14(2):e1002232.

34. Barrientos-Gutierrez T. Expected population weight and diabetes impact of the 1-peso-per-litre tax to sugar sweetened beverages in Mexico. PLoS Med. 2017;12(5):e0176336. https://doi.org/10.1371/journal.pone.0176336.

35. Thomas R CKCealCJ, Papanicolas I, Smith PC, editors. Health system efficiency: How to make measurement matter for policy and management [Internet]. Copenhagen (Denmark): European Observatory on Health Systems and Policies; 2016. (Health Policy Series, No. 46.) 6. Available from: https://www.ncbi.nlm.nih.gov/books/NBK436886/.

36. Moher D, Liberati A, Tetzlaff J, Altman DG. Preferred reporting items for systematic reviews and meta-analyses: the PRISMA statement. PLoS Med. 2009;6(7):e1000097. https://doi.org/10.1371/journal.pmed.1000097.

37. Babineau J. Product Review: Covidence (Systematic Review Software). J Can Health Libraries Assoc Journal de l'Association des bibliothèques de la santé du Canada 2014, 35(2). https://www.ncbi.nlm.nih.gov/pmc/articles/PMC2 707599/pdf/pmed.1000097.pdf.

38. Covidence systematic review software. In. Melbourne, Australia: Veritas Health Innovation.

39. Brennan A, Chick SE, Davies R. A taxonomy of model structures for economic evaluation of health technologies. Health Econ. 2006;15(12):1295-310.

40. Afshin A, Micha R, Khatibzadeh S, Fahimi S, Shi P, Powles J, Singh G, Yakoob MY, Abdollahi M, Al-Hooti S et al. The impact of dietary habits and metabolic risk factors on cardiovascular and diabetes mortality in countries of the Middle East and North Africa in 2010: A comparative risk assessment analysis. BMJ Open. 2015;5(5):e006385.
41. Barrientos-Gutierrez T, Zepeda-Tello R, Rodrigues ER, Colchero-Aragones A, Rojas-Martönez R, Lazcano-Ponce E, et al. Expected population weight and diabetes impact of the 1-peso-per-litre tax to sugar sweetened beverages in Mexico. PLoS One. 2017;12(5).

42. Basu S, Lewis K. Reducing added sugars in the food supply through a capand-trade approach. Am J Public Health. 2014;104(12):2432-8. https://doi. org/10.2105/AJPH.2014.302170

43. Basu S, Seligman H, Bhattacharya J. Nutritional policy changes in the supplemental nutrition assistance program: a microsimulation and costeffectiveness analysis. Med Decis Mak. 2013;33(7):937-48. https://doi.org/1 0.1177/0272989X13493971.

44. Basu S, Vellakkal S, Agrawal S, Stuckler D, Popkin B, Ebrahim S. Averting obesity and type 2 diabetes in India through sugar-sweetened beverage taxation: an economic-epidemiologic modeling study. PLoS Med. 2014;11(1): e1001582. https://doi.org/10.1371/journal.pmed.1001582.

45. Breeze PR, Thomas C, Squires H, Brennan A, Greaves C, Diggle P, et al. Costeffectiveness of population-based, community, workplace and individual policies for diabetes prevention in the UK. Diabet Med. 2017;34(8):1136-44. https://doi.org/10.1111/dme.13349.

46. Briggs AD, Mytton OT, Kehlbacher A, Tiffin R, Rayner M, Scarborough P. Overall and income specific effect on prevalence of overweight and obesity of $20 \%$ sugar sweetened drink tax in UK: econometric and comparative risk assessment modelling study. BMJ. 2013;347(oct31 4):f6189. https://doi.org/1 0.1136/bmj.f6189

47. Briggs AD, Mytton OT, Madden D, O'Shea D, Rayner M, Scarborough P. The potential impact on obesity of a $10 \%$ tax on sugar-sweetened beverages in Ireland, an effect assessment modelling study. BMC Public Health. 2013; 13(1):860. https://doi.org/10.1186/1471-2458-13-860.

48. Briggs ADM, Mytton OT, Kehlbacher A, Tiffin R, Elhussein A, Rayner M, et al. Health impact assessment of the UK soft drinks industry levy: a comparative risk assessment modelling study. Lancet Public Health. 2017;2(1):e15-22. https://doi.org/10.1016/S2468-2667(16)30037-8.

49. Brown V, Ananthapavan J, Veerman L, Sacks G, Lal A, Peeters A, Backholer K, Moodie M. The Potential Cost-Effectiveness and Equity Impacts of Restricting Television Advertising of Unhealthy Food and Beverages to Australian Children. Nutrients. 2018;10(5):622.

50. Cobiac $L$, Tam K, Veerman L, Blakely T. Taxes and Subsidies for Improving Diet and Population Health in Australia: A Cost-Effectiveness Modelling Study. PLoS Med. 2017;14(2).

51. Collins B, Capewell S, O'Flaherty M, Timpson H, Razzaq A, Cheater S, et al. Modelling the Health Impact of an English Sugary Drinks Duty at National and Local Levels. PLOS ONE [Electronic Resource]. 2015;10(6): e0130770.

52. Crino M, Mantilla Herrera AM, Ananthapavan J, Wu JHY, Neal B, Yong Yi L, et al. Modelled cost-effectiveness of a package size cap and a kilojoule reduction intervention to reduce energy intake from sugar-sweetened beverages in Australia. Nutrients. 2017:9(9):1-17.

53. Gortmaker SL, Long MW, Resch SC, Ward ZJ, Cradock AL, Barrett JL, et al. Cost effectiveness of childhood obesity interventions: evidence and methods for CHOICES. Am J Prev Med. 2015;49(1):102-11. https://doi.org/1 0.1016/j.amepre.2015.03.032.

54. Gortmaker SL, Wang YC, Long MW, Giles CM, Ward ZJ, Barrett JL, et al. Three interventions that reduce childhood obesity are projected to save more than they cost to implement. Health Aff. 2015;34(11):1932-9. https:// doi.org/10.1377/hlthaff.2015.0631.

55. Kristensen AH, Flottemesch TJ, Maciosek MV, Jenson J, Barclay G, Ashe M, et al. Reducing childhood obesity through U.S. federal policy: a microsimulation analysis. Am J Prev Med. 2014;47(5):604-12. https://doi. org/10.1016/j.amepre.2014.07.011.

56. Lal A, Mantilla-Herrera AM, Veerman L, Backholer K, Sacks G, Moodie M, et al. Modelled health benefits of a sugar-sweetened beverage tax across different socioeconomic groups in Australia: a cost-effectiveness and equity analysis. PLoS Med. 2017;14(6):1-17.

57. Lee BY, Ferguson MC, Hertenstein DL, Adam A, Zenkov E, Wang Pl, et al. Simulating the impact of sugar-sweetened beverage warning labels in three cities. Am J Prev Med. 2018:54(2):197-204. https://doi.org/10.1016/.jamepre.2017.11.003.

58. Lieffers JRL, Ekwaru JP, Ohinmaa A, Veugelers PJ. The economic burden of not meeting food recommendations in Canada: The cost of doing nothing. PLoS One. 2018;13(4).

59. Long MW, Gortmaker SL, Ward ZJ, Resch SC, Moodie ML, Sacks G, et al. Cost effectiveness of a sugar-sweetened beverage excise tax in the U.S. 
Am J Prev Med. 2015;49(1):112-23. https://doi.org/10.1016/j.amepre.2015. 03.004.

60. Ma Y, He FJ, Yin Y, Hashem KM, MacGregor GA. Gradual reduction of sugar in soft drinks without substitution as a strategy to reduce overweight, obesity, and type 2 diabetes. A modelling study. Lancet Diabetes Endocrinol. 2016:4(2):105-14. https://doi.org/10.1016/S2213-8587(15)00477-5.

61. Magnus A, Moodie ML, Ferguson M, Cobiac LJ, Liberato SC, Brimblecombe J. The economic feasibility of price discounts to improve diet in Australian Aboriginal remote communities. Aust N Z J Public Health. 2016;40(S1):S3641. https://doi.org/10.1111/1753-6405.12391.

62. Manyema M, Veerman $\sqcup$, Chola L, Tugendhaft A, Sartorius B, Labadarios D, et al. The potential impact of a $20 \%$ tax on sugar-sweetened beverages on obesity in South African adults: A mathematical model. PLoS One. 2014;9(8).

63. Manyema M, Veerman $\sqcup$, Tugendhaft A, Labadarios D, Hofman KJ. Modelling the potential impact of a sugar-sweetened beverage tax on stroke mortality, costs and health-adjusted life years in South Africa. BMC Public Health. 2016;16(1):1-10.

64. Nomaguchi T, Cunich M, Zapata-Diomedi B, Veerman JL. The impact on productivity of a hypothetical tax on sugar-sweetened beverages. Health Policy. 2017;121(6):715-25. https://doi.org/10.1016/j.healthpol.2017.04.001.

65. Pearson-Stuttard J, Bandosz P, Rehm CD, Penalvo J, Whitsel L, Gaziano T, et al. Reducing us cardiovascular disease disparities through dietary policy. BMC Public Health. 2016;16:405.

66. Penalvo JL, Cudhea F, Micha R, Rehm CD, Afshin A, Whitsel L, et al. The potential impact of food taxes and subsidies on cardiovascular disease and diabetes burden and disparities in the United States. BMC Med. 2017;15(1): 208. https://doi.org/10.1186/s12916-017-0971-9.

67. Sacks G, Veerman JL, Moodie M, Swinburn B. Traffic-light nutrition labelling and junk-food tax: a modelled comparison of costeffectiveness for obesity prevention. Int J Obes. 2011;35(7):1001-9. https://doi.org/10.1038/ijo.2010.228.

68. Sanchez-Romero LM, Penko J, Coxson PG, Fernandez A, Mason A, Moran AE, et al. Projected impact of Mexico's sugar-sweetened beverage tax policy on diabetes and cardiovascular disease: a modeling study. PLoS Med Public Library of Science. 2016;13(11):e1002158.

69. Schwendicke F, Thomson WM, Broadbent JM, Stolpe M. Effects of taxing sugar-sweetened beverages on caries and treatment costs. J Dent Res. 2016;95(12):1327-32. https://doi.org/10.1177/0022034516660278.

70. Veerman JL, Sacks G, Antonopoulos N, Martin J. The impact of a tax on sugar-sweetened beverages on health and health care costs: A modelling study. PLoS One. 2016;11(4).

71. Wang YC, Coxson P, Shen Y-M, Goldman L, Bibbins-Domingo K. A pennyper-ounce tax on sugar-sweetened beverages would cut health and cost burdens of diabetes. Health Aff. 2012;31(1):199-207. https://doi.org/10.1377/ hlthaff.2011.0410.

72. Wilson KJ, Brown HS, Bastida E. Cost-effectiveness of a community-based weight control intervention targeting a low-socioeconomic-status Mexicanorigin population. Health Promot Pract. 2015;16(1):101-8. https://doi.org/1 $0.1177 / 1524839914537274$

73. Wright DR, Kenney EL, Giles CM, Long MW, Ward ZJ, Resch SC, et al. Modeling the cost effectiveness of child care policy changes in the U.S. Am J Prev Med. 2015;49(1):135-47. https://doi.org/10.1016/j.amepre.2015.03.016.

74. Malik VS, Schulze MB, Hu FB. Intake of sugar-sweetened beverages and weight gain: a systematic review. Am J Clin Nutr. 2006;84(2):274-88. https:// doi.org/10.1093/ajen/84.2.274

75. Muennig P, Lubetkin E, Jia H, Franks P. Gender and the burden of disease attributable to obesity. Am J Public Health. 2006;96(9):1662-8. https://doi. org/10.2105/AJPH.2005.068874.

76. Jiwani SS, Carrillo-Larco RM, Hernandez-Vasquez A, Barrientos-Gutierrez T, Basto-Abreu A, Gutierrez L, et al. The shift of obesity burden by socioeconomic status between 1998 and 2017 in Latin America and the Caribbean: a cross-sectional series study. Lancet Glob Health. 2019;7(12): e1644-54. https://doi.org/10.1016/S2214-109X(19)30421-8.

77. Heise TL, Katikireddi SV, Pega F, Gartlehner G, Fenton C, Griebler U, et al. Taxation of sugar-sweetened beverages for reducing their consumption and preventing obesity or other adverse health outcomes. Cochrane Database Syst Rev. 2016;8.

78. von Philipsborn P, Stratil JM, Burns J, Busert LK, Pfadenhauer LM, Polus S, et al. Environmental interventions to reduce the consumption of sugarsweetened beverages and their effects on health. Cochrane Database Syst Rev. 2019;6:CD012292.
79. Malik VS, Popkin BM, Bray GA, Despres JP, Willett WC, Hu FB. Sugarsweetened beverages and risk of metabolic syndrome and type 2 diabetes: a meta-analysis. Diabetes Care. 2010;33(11):2477-83. https://doi.org/10.2337/ dc10-1079.

80. Yin J, Zhu Y, Malik V, Li X, Peng X, Zhang FF, et al. Intake of SugarSweetened and Low-Calorie Sweetened Beverages and Risk of Cardiovascular Disease: A Meta-Analysis and Systematic Review. Adv Nutr. 2021;12(1):89-101.

81. Carter R, Moodie M, Markwick A, Magnus A, Vos T, Swinburn B, et al. Assessing cost-effectiveness in obesity (ACE-obesity): an overview of the ACE approach, economic methods and cost results. BMC Public Health. 2009;9(1):419. https://doi.org/10.1186/1471-2458-9-419.

82. Backholer K, Sarink D, Beauchamp A, Keating C, Loh V, Ball K, et al. The impact of a tax on sugar-sweetened beverages according to socioeconomic position: a systematic review of the evidence. Public Health Nutr. 2016;19(17):3070-84. https://doi.org/10.1017/S136898001600104X.

83. Du M, Tugendhaft A, Erzse A, Hofman KJ. Sugar-sweetened beverage taxes: industry response and tactics. Yale J Biol Med. 2018;91(2):185-90.

84. Bridge G, Lomazzi M, Bedi R. Implementation of a sugar-sweetened beverage tax in low- and middle-income countries: recommendations for policymakers. J Public Health Policy. 2020;41(1):84-97. https://doi.org/10.1 057/s41271-019-00196-z.

85. Stanaway JD, Afshin A, Gakidou E, Lim SS, Abate D, Abate KH, et al. Global, regional, and national comparative risk assessment of 84 behavioural, environmental and occupational, and metabolic risks or clusters of risks for 195 countries and territories, 1990\&\#x2013;2017: a systematic analysis for the Global Burden of Disease Study 2017. Lancet. 2018;392(10159):1923-94. https://doi.org/10.1016/S0140-6736(18)32225-6.

86. Webber L, Mytton OT, Briggs ADM, Woodcock J, Scarborough P, McPherson $K$, et al. The Brighton declaration: the value of non-communicable disease modelling in population health sciences. Eur J Epidemiol. 2014;29(12):86770. https://doi.org/10.1007/s10654-014-9978-0.

87. Lopez ADMC, Ezzati M, et al. Editors. Washington (DC). The International Bank for Reconstruction and Development / the World Bank. New York: Oxford University Press; 2006

88. Tobacco Free Initiative (TFI). Implementing tobacco control [https://www. who.int/tobacco/control/en/].

\section{Publisher's Note}

Springer Nature remains neutral with regard to jurisdictional claims in published maps and institutional affiliations.
Ready to submit your research? Choose BMC and benefit from:
- fast, convenient online submission
- thorough peer review by experienced researchers in your field
- rapid publication on acceptance
- support for research data, including large and complex data types
- gold Open Access which fosters wider collaboration and increased citations
- maximum visibility for your research: over $100 \mathrm{M}$ website views per year
At BMC, research is always in progress.
Learn more biomedcentral.com/submissions 